\title{
CENTRAL LINE ASSOCIATED BLOODSTREAM INFECTIONS IN PEDIATRIC UNITS IN GREECE
}

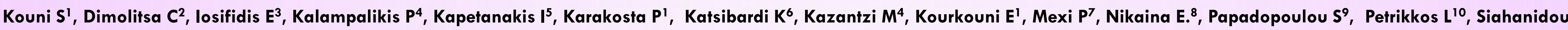
$\mathrm{T}^{8}$, Skordala $\mathrm{M}^{11}$, Tragiannidis $\mathrm{A}^{12}$, Tsolia $\mathrm{M}^{13}$, Zanikos $\mathrm{K}^{14}$, Zaoutis E. $\mathrm{T}^{1}$

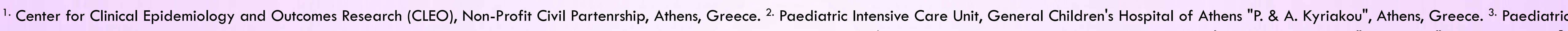

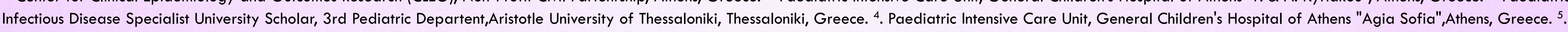

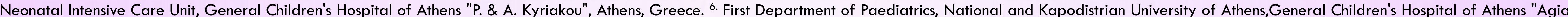

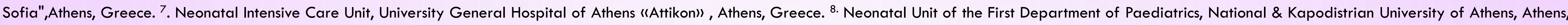

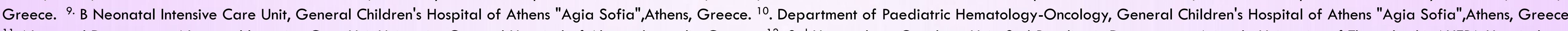

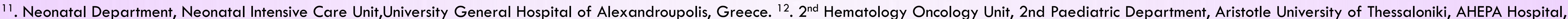

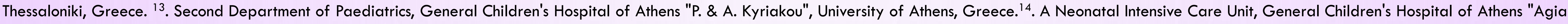
Sofia",Athens, Greece.

\section{Background:}

Healthcare-associated infections (HAl) are associated with increased morbidity and mortality and excess costs. Central line associated bloodstream infections (CLABSI) are the most common $\mathrm{HAl}$ in neonates and children. The broad objective of this study was to develop a CLABSI collaborative in neonatal and pediatric intensive care units and pediatric oncology units. We sought to establish national benchmark data around rates of CLABSI.

\section{Methods:}

Active surveillance for CLABSI was conducted from June 2016 to February 2017. A collaborative of 14 NICUs, 5 PICUs and 6 Pediatric Oncology Units (ONCs) participated in the program. Surveillance definitions of central line $(\mathrm{CL})$, central line utilization (CLU) ratio, CLABSI event and CLABSI rate based on 2014 Centers for Disease Control and Preventions' National Healthcare Safety Network criteria. $\mathrm{CL}$ days and patient days were collected daily from medical records and microbiologic data including the sensitivities of the isolated organisms, were also recorded.
Table 1. Enrolled facilities contributing data used in this report, during the surveillance period June 2016 to February 2017

\begin{tabular}{|c|c|c|c|c|c|c|c|c|c|}
\hline $\begin{array}{c}\text { Type of } \\
\text { acute care } \\
\text { facility }\end{array}$ & $\begin{array}{c}\text { No of } \\
\text { locations }\end{array}$ & $\begin{array}{c}\text { No of } \\
\text { CLABSI }\end{array}$ & $\begin{array}{c}\text { No of } \\
\text { MBI } \\
\text { CLABSI }\end{array}$ & $\begin{array}{c}\text { Total } \\
\text { Central } \\
\text { line days }\end{array}$ & $\begin{array}{c}\text { Total } \\
\text { patient } \\
\text { days }\end{array}$ & $\begin{array}{c}\text { Total } \\
\text { antibiotic } \\
\text { days }\end{array}$ & $25 \%$ & median & $75 \%$ \\
\hline NICUs & 14 & 55 & 0 & 9141 & 62368 & 23027 & 291 & 359 & 401 \\
\hline PICUs & 4 & 21 & 0 & 3430 & 5059 & 2977 & 333 & 563 & 848 \\
\hline ONCs & 6 & 35 & 15 & 12572 & 14881 & 8725 & 445 & 477 & 619 \\
\hline ALL UNITS & 24 & 111 & 15 & 25143 & 82308 & 34729 & & & \\
\hline
\end{tabular}

$L O T=($ no of calendar days in which antibiotics were received/total number of patient days)*1000

Mucosal Barrier Injury Laboratory

\section{Results:}

A total of 111 CLABSI episodes were recorded. Among pediatric oncology patients, a total of $35 \mathrm{CLABSI}$ were identified during the study period, 15/35 (42.86\%) were classified as MBI-LCBI (Table 1). The monthly CLABSI rates for all units across the whole surveillance period are presented in Figure 1. Stratified analysis by ward type (NICUs, PICUs and ONCs) revealed that the higher CLABSI rates were noticed in the PICUs and NICUs, and the higher central line utilization ratio was in ONCs (Table 2). The stratification of CLABSI rates among the units were 6.02 for NICUs, 6.12 for PICUs and 2.78 infections per 1000 central line $(C L)$ days for ONCs (Table 2).

Figure 1. Monthly CLABSI rate and overall CLABSI rate among all units

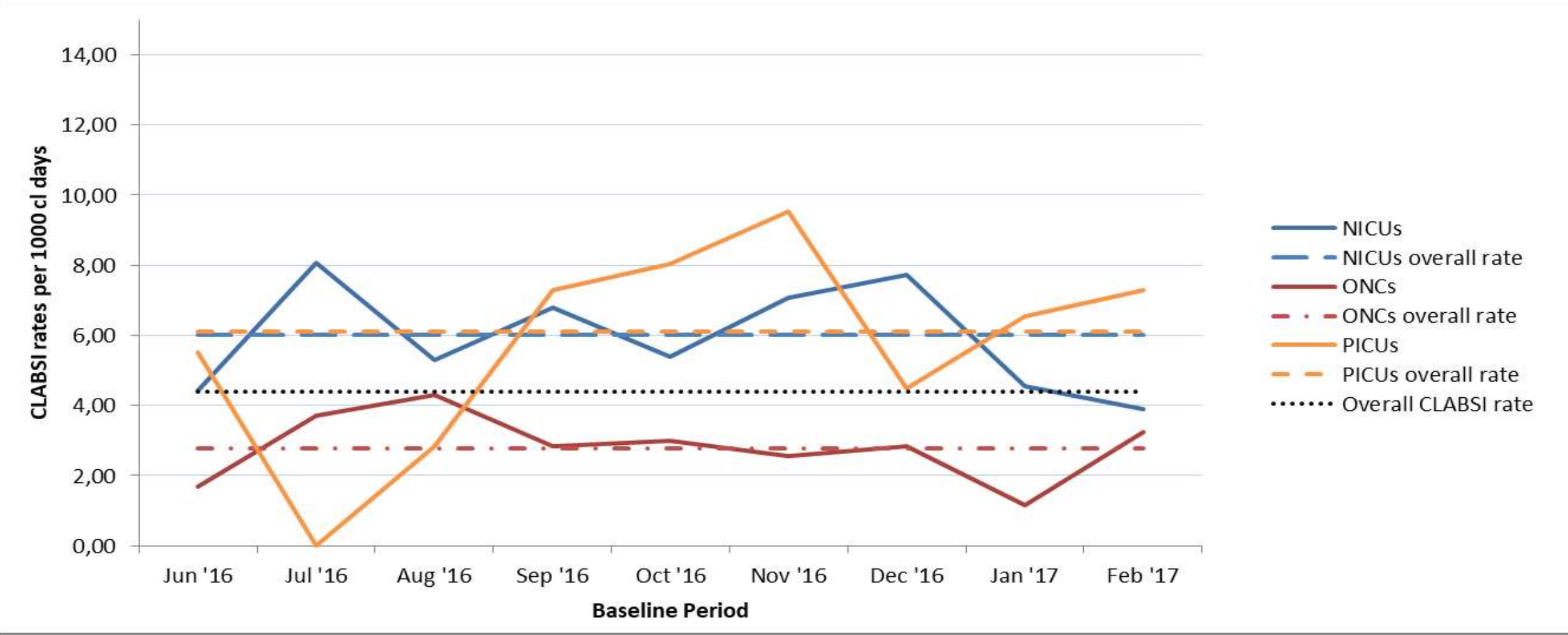

Conclusions:

Nationally representative CLABSI rates were determined for pediatric patients. Of significant concern was the identification of high rates of carbapenem-resistant organisms. These data could be used to benchmark and serve as baseline data for the design and evaluation of infection control and antimicrobial stewardship interventions.
A total of 123 pathogens isolated in 111 CLABSI episodes were observed among all units. Gram positive cocci were ONCs. Overall $37 \%$ of gram-negative pathogens were resistant to carbapenems and $38.5 \%$ were resistant to third generation cephalosporins.

Table 2. Pooled means and key percentiles of the distribution

\begin{tabular}{|l|c|c|c|c|c|c|c|c|}
\hline $\begin{array}{l}\text { Type of } \\
\begin{array}{l}\text { acute } \\
\text { care } \\
\text { facility }\end{array}\end{array}$ & \multicolumn{9}{|c|}{ CLABSI RATE } & \multicolumn{5}{c|}{ CLU RATIO } \\
\hline & $\begin{array}{c}\text { Pooled } \\
\text { mean }\end{array}$ & $25 \%$ & Median & $75 \%$ & $\begin{array}{c}\text { Pooled } \\
\text { mean }\end{array}$ & $25 \%$ & Median & $75 \%$ \\
\hline NICUs & 6.02 & 3.83 & 6.96 & 9.9 & 0.15 & 0.06 & 0.13 & 0.26 \\
\hline PICUs & 6.12 & 4.77 & 6.24 & 16.5 & 0.68 & 0.38 & 0.72 & 0.89 \\
\hline ONCS & 2.78 & 1.65 & 2.48 & 3.65 & 0.84 & 0.79 & 0.83 & 0.97 \\
\hline $\begin{array}{l}\text { CLABSI RATE= (no of CLABSIs/central line days)*1000 } \\
\text { CLU RATIO= (no of central line days/no of patient days) }\end{array}$
\end{tabular}
CIU RATIO $=$ (no of central line days/ no of patient days) 